\title{
Ethylene signaling is required for the acceleration of cell death induced by the activation of AtMEK5 in Arabidopsis
}

\author{
Hongxia Liu ${ }^{1, *}$, Ying Wang ${ }^{1, *}$, Juan $\mathrm{Xu}^{1}$, Tongbing $\mathrm{Su}^{1}$, Guoqin Liu ${ }^{1}$, Dongtao Ren ${ }^{1}$ \\ ${ }^{1}$ State Key Laboratory of Plant Physiology and Biochemistry, College of Biological Sciences, China Agricultural University, Bei- \\ jing 100094, China
}

Mitogen-activated protein kinases (MAPKs) are involved in the regulation of plant growth, development and responses to a wide variety of stimuli. In a conditional gain-of-function transgenic system, the activation of AtMEK5, a MAPK kinase, can in turn activate endogenous AtMAPK3 and AtMAPK6, and can lead to a striking increase in ethylene production and induce hypersensitive response (HR)-like cell death in Arabidopsis. However, the role of the increased ethylene production in regulating this HR-like cell death remains unknown. Using Arabidopsis transgenic plants that express AtMEK5 ${ }^{\mathrm{DD}}$, an active mutant of AtMEK5 that is under the control of a steroid-inducible promoter, we tested the contribution of ethylene to cell death. We found that ethylene biosynthesis occurs before cell death. Cell death was delayed by inhibiting AtMEK5-induced ethylene production using inhibitors of ACC-synthases, ACCoxidases or ethylene receptors. In the mutants $A t M E K 5^{D D} / e t r 1-1$ and $A t M E K 5^{D D} / e i n 2-1$, both of which showed insensitivity to ethylene, the expression of AtMEK5 ${ }^{\mathrm{DD}}$ protein, activity of AtMAPK3 and AtMAPK6, and ethylene production were the same as those seen in $A t M E K 5^{D D}$ transgenic plants, but cell death was also delayed. These data suggest that ethylene signaling perception is required to accelerate cell death that is induced by AtMEK5 activation.

Keywords: cell death, ethylene and ethylene signaling, mitogen-activated protein kinase, AtMEK5, Arabidopsis

Cell Research (2008) 18:422-432. doi: 10.1038/cr.2008.29; published online 12 February 2008

\section{Introduction}

Cell death is a fundamental biological process in plant development and is involved in responses to diverse stimuli, including biotic and abiotic stresses $[1,2]$. To prevent pathogen invasion, plants have developed a complex array of defense responses that include generation of reactive oxygen species (ROS), activation of defense genes, production of phytoalexins, and rapid cell death, which is also known as the hypersensitive response (HR) [3-8]. HR-like cell death confines the pathogen by stopping its spread from the site of the attempted infection. The results obtained from kinase activity assays and pharmacological studies that use specific inhibitors of protein kinases and phosphatases have implicated protein

\footnotetext{
*These two authors contributed equally to this work. Correspondence: Dongtao Ren

Tel: 0086-10-62733794; Fax: 0086-10-62891332

E-mail: ren@cau.edu.cn

Received 4 June 2007; revised 3 September 2007; accepted 25 September 2007; published online 12 February 2008
}

phosphorylation and dephosphorylation in the induction of defense responses in plants [9-11]. Mitogen-activated protein kinase (MAPK) cascades are evolutionarily conserved signaling modules that transduce the extracellular stimuli into intracellular signals to regulate a wide variety of cellular processes in all eukaryotes [12-14]. Pathogens and pathogen-derived elicitors can activate MAPK and induce HR-like cell death, while kinase activity inhibitors block HR-like cell death. Such evidence suggests that the activation of MAPK cascades is involved in the signaling pathways that lead to HR-like cell death [15-18].

MAPK cascades are composed of three functional interlinked protein kinases: MAPKs, MAPK kinases (MAPKKs or MEKs) and MAPKK kinases (MAPKKKs or MEKKs). MAPKKKs can be activated by different mechanisms, such as phosphorylation or interaction with G-protein or receptors. MAPKKKs activate MAPKK through the phosphorylation of its two serine/threonine residues in the $\mathrm{S} / \mathrm{T}-\mathrm{X}_{3-5}-\mathrm{S} / \mathrm{T}$ motif. MAPKKs are dualspecificity kinases that activate MAPK through the phosphorylation of threonine and tyrosine residues in 
the T-X-Y motif. Activated MAPKs may be translocated to the nucleus to phosphorylate and thereby regulate the activity of specific transcription factor(s). Alternatively, activated MAPKs can remain in the cytoplasm to phosphorylate cytoskeleton-associated proteins or regulatory enzymes and to initiate cellular responses [19].

The results of gain-of-function studies have revealed that expression of an active mutant of NtMEK2, a MAPKK in tobacco, induces HR-like cell death that is preceded by the activation of endogenous WIPK, Ntf4 and SIPK, all of which are downstream MAPKs of NtMEK2 [20, 21]. Overexpression of SIPK or Ntf4 in tobacco leaves leads to increased activity of SIPK or Ntf4 that is sufficient to induce HR-like cell death [21, 22]. Although the overexpression of WIPK alone fails to elicit cell death, co-expression of WIPK with the active mutant of NtMEK2 leads to accelerated HR-like cell death [17]. In addition, by using the PVX-induced gene silencing technique, Jin and colleagues reported that the suppression of all three known components in the NtMEK2SIPK/WIPK pathway attenuated $\mathrm{N}$ gene-mediated TMV resistance, possibly by regulating HR-like cell death [23]. Based on phylogenetic analysis, Arabidopsis AtMEK4 and AtMEK5 and tomato LeMKK2 are very similar to tobacco NtMEK2, and they belong to MAPKK group C [24-26]. The expression of active mutants of LeMKK2, AtMEK4, or AtMEK5 in transgenic plants causes HRlike cell death and activates their respective downstream MAPKs: LeMPK2 and LeMPK3, AtMAPK6, and AtMAPK3 [24, 25]. LeMPK2 and AtMAPK6 are very similar to SIPK, and LeMPK3 and AtMAPK3 are very similar to WIPK. Overexpression of LeMKK4, which is not related phylogenetically to LeMKK2 and belongs to the MAPKK group D, also elicits HR-like cell death and activates LeMPK2 and LeMPK3 in tomato [25]. We have observed that the activation of AtMEK7 and AtMEK9, which also belong to the MAPKK group $\mathrm{D}$, can induce HR-like cell death and activate AtMAPK3 and AtMPAK6 in transient transformed tobacco plants and permanent transgenic Arabidopsis plants (our unpublished data). Collectively, these results indicate that MAPK cascades are involved in the regulation of HR-like cell death in plants.

Ethylene, a gaseous phytohormone, has important roles in regulating plant growth and development, and participates in plant responses to both biotic and abiotic stresses $[27,28]$. There are two crucial steps in the control of ethylene biosynthesis. The first is the rate-limiting conversion of $S$-adenosyl-L-methionine (SAM) to 1-aminocyclopropane-1-carboxylic acid (ACC) by ACC synthase (ACS) [29]. The second is the oxidative cleavage of ACC by ACC oxidase (ACO) to form ethylene,
$\mathrm{CO}_{2}$ and cyanide $[29,30]$. The acceleration of ethylene biosynthesis in response to environment stresses and endogenous cues is often related to the increased activity of ACS that is caused by the post-transcriptional regulation and activation of ACS and ACO [28]. In tomato cells, treatment with inhibitors of protein kinases prevented the increase of ACS activity that is induced by a fungal elicitor, whereas treatment with a phosphatase inhibitor stimulated ACS activity in the absence of the elicitor [31]. Ethylene production in NN tobacco plants that were infected with TMV correlated with SIPK/WIPK activation and overexpression of $A C S s$ and ACOs [18, 32, 33]. Expression of the active mutant of NtMEK2 induced rapid activation of SIPK/WIPK, accelerated ethylene biosynthesis and caused HR-like cell death in transgenic tobacco plants $[18,20]$. Recently, Liu and Zhang reported that ethylene biosynthesis, which was induced by the activation of NtMEK2, was the result of phosphorylation of ACS6 by AtMAPK6 [34]. These results suggest that protein phosphorylation and dephosphorylation are involved in the regulation of stress-induced ethylene biosynthesis.

It has been established that the activation of NtMEK2 and its Arabidopsis orthologs (AtMEK4 and AtMEK5) are involved in ethylene biosynthesis, $\mathrm{H}_{2} \mathrm{O}_{2}$ generation and HR-like cell death $[18,24,34]$. However, the relationship between ethylene and this HR-like cell death is not yet fully understood. In this report, we present evidence, obtained from transgenic Arabidopsis plants that carry the steroid-inducible promoter controlled $A t$ $M E K 5^{D D}$, for the role of ethylene in regulating HR-like cell death. We found that induction of AtMEK $5^{\mathrm{DD}}$, an active mutant of AtMEK5, led to rapid activation of endogenous AtMAPK3 and AtMAPK6, a dramatic increase in ethylene production and ultimately HR-like cell death. Cell death was delayed by using inhibitors of ethylene biosynthesis and by blocking ethylene perception with ethylene receptor antagonist or ethylene receptor mutants. These results suggest that ethylene and its signaling pathways have important roles in AtMEK5-induced HR-like cell death.

\section{Results}

Activation of AtMEK5 induces ethylene biosynthesis and cell death

In a previous study, we showed that the expression of AtMEK $5^{\text {DD }}$, an active form of AtMEK5, could activate downstream endogenous AtMAPK3 and AtMAPK6 and cause HR-like cell death in transgenic Arabidopsis plants [24]. More recently, several investigators have reported that activation of NtMEK2, as well as its orthologs in Arabidopsis (AtMEK4 and AtMEK5), can accelerate 
ethylene biosynthesis in transgenic plants $[18,34]$. In this instance, ethylene production was the result of phosphorylation of ACS6 by activated AtMAPK6 and the resultant accumulation of ACS protein in Arabidopsis [34]. However, the molecular mechanisms that link activation of the MAPK cascade and induction of HR-like cell death remain to be elucidated. In this study, we used transgenic Arabidopsis plants that carried AtMEK5 ${ }^{D D}$ (the mutated gene that encodes the active AtMEK5 protein), $A t M E K 5^{K R}$ (the mutated gene that encodes the inactive AtMEK 5 protein) and AtMEK5 $5^{W T}$ (the wild-type gene that encodes the AtMEK5 protein) under control of the steroid-induced promoter to better understand the relationship between ethylene production and HR-like cell death [24]. We used the Evans blue staining method to detect cell death. Small areas of cell death were detected on the leaf edge of $A t M E K 5^{D D}$ plants $24 \mathrm{~h}$ after Dexamethasone (DEX) treatment and the whole leaf died after $36 \mathrm{~h}$ after DEX treatment (Figure 1A). By contrast, leaves from $A t M E K 5^{K R}, A t M E K 5^{W T}$ and Vector transgenic plants after DEX treatment, and leaves from AtMEK $5^{D D}$ $A t M E K 5^{K R}, A t M E K 5^{W T}$ and Vector transgenic plants that had been incubated in distilled water with $0.05 \%$ ethanol (solvent of DEX), showed no sign of cell death (Figure 1A). We also used electrolyte leakage, an indicator of membrane damage, to show the extent of cell death. As shown in Figure 1B, electrolyte started to leak from leaves from AtMEK $5^{D D}$ transgenic plants at $24 \mathrm{~h}$ after DEX treatment. This result also demonstrates that cell death starts in leaves from $A t M E K 5^{D D}$ plants at $24 \mathrm{~h}$ after DEX treatment. The ethylene biosynthesis was measured at various time points, as indicated. There was a dramatic
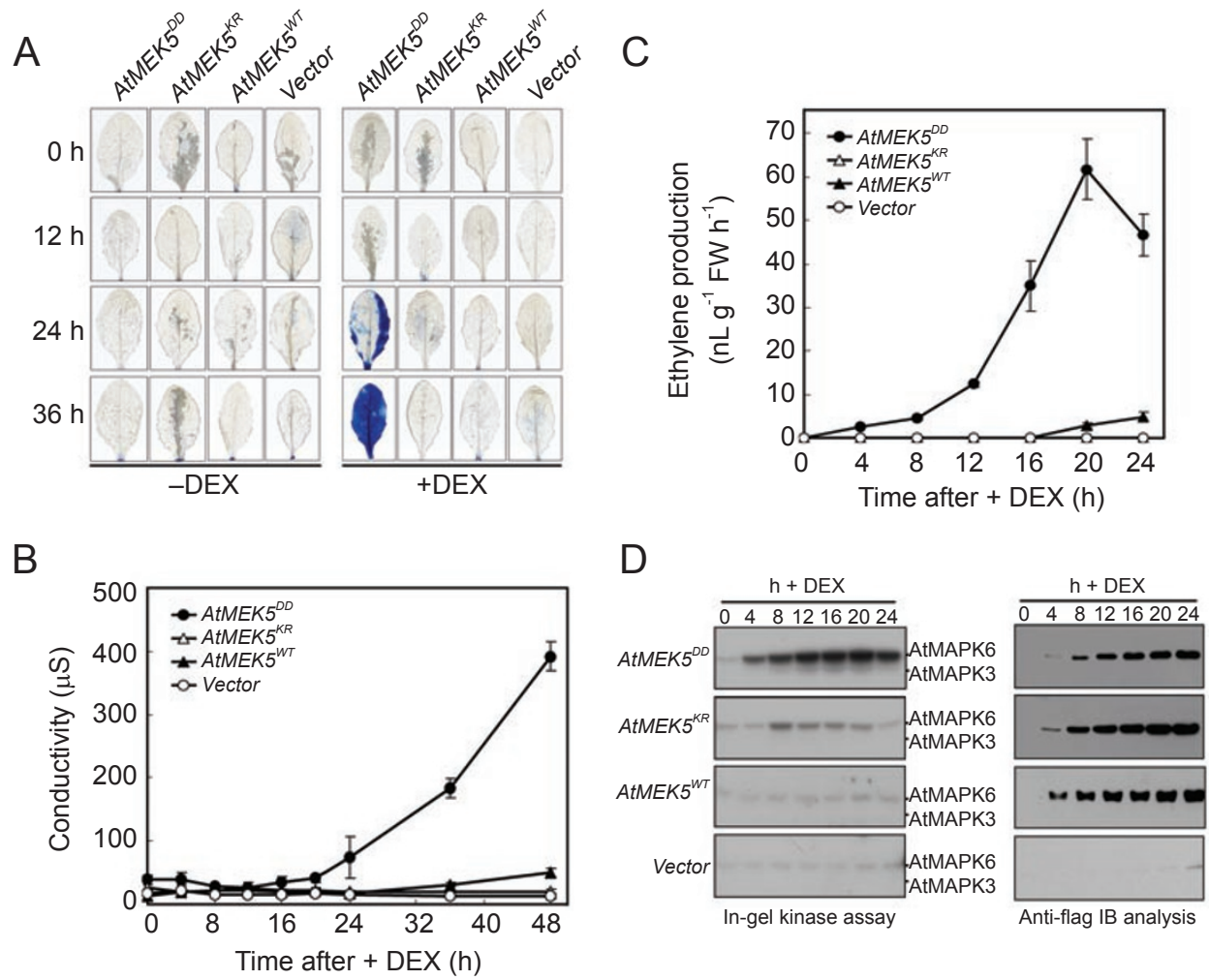

Figure 1 Induction of AtMEK5 expression in transgenic Arabidopsis plants leads to endogenous AtMAPK3 and AtMAPK6 activation, ethylene biosynthesis, electrolyte leakage and cell death. (A) The leaves from AtMEK5 ${ }^{D D}, A t M E K 5^{K R}, A t M E K 5^{W T}$ and Vector control transgenic plants were stained with Evans blue after DEX (as +DEX) or $0.05 \%$ ethanol (as -DEX) treatments. Cell death is indicated in blue. (B) Electrolyte leakage is associated with cell death in transgenic plants. Measurements of electrolyte leakage were performed as described in the Materials and Methods section. The results present the means and standard deviations from triplicate samples. (C) A time course analysis of ethylene production in leaves from transgenic Arabidopsis plants treated with DEX. The results present the means and standard deviations from triplicate samples. (D) A time course analysis of AtMEK5 mutants induction and endogenous AtMAPK6 and AtMAPK3 activation in leaves from transgenic Arabidopsis plants after DEX (as +DEX ) or $0.05 \%$ ethanol (as -DEX) treatments. The expression of AtMEK5 mutants was monitored by immunoblot analysis using anti-Flag M2 antibody (right). The kinase activity of endogenous AtMAPK3 and AtMAPK6 was determined by an in-gel kinase assay (left). 
increase in ethylene biosynthesis in leaves from AtME$K 5^{D D}$ plants (Figure 1C). Ethylene could be detected in leaves $4 \mathrm{~h}$ after DEX treatment. Thereafter, the rate of ethylene production progressively increased and reached its highest level after $20 \mathrm{~h}$. By contrast, over the entire period, ethylene was not detected in leaves of any control plants (Figure 1C). Using an in-gel kinase assay, it can be seen that the expression of AtMEK $5^{\mathrm{DD}}$ leads to rapid activation of endogenous AtMAPK3 and AtMAPK6, whereas expression of AtMEK $5^{\mathrm{KR}}$ and AtMEK $5^{\mathrm{WT}}$ only shows a basal level of AtMAPK6 activity (Figure 1D, left). Immunoblot analysis with anti-Flag antibody revealed that the expression levels of AtMEK $5^{\text {DD }}$, AtME$\mathrm{K} 5^{\mathrm{WT}}$ and AtMEK $5^{\mathrm{KR}}$ induced by DEX are similar (Figure $1 \mathrm{D}$, right). These data indicate that ethylene biosynthesis can be induced by activation of AtMEK 5 and the downstream MAPKs AtMAPK3 and AtMAPK6. Furthermore, ethylene biosynthesis occurs earlier than HR-like cell death.

Kinetics of transcript accumulation for genes of ethylene biosynthesis and the ethylene responses that are induced by the activation of AtMEK5

Stress-stimulated ethylene production occurs owing to an increase in the activity of ACOs and ACSs, which is caused by post-translational regulation or transcriptional activation $[18,35,36]$. The key steps of ethylene biosynthesis are controlled by ACS and ACO [28, 29]. The basal activity of ACS is very low in tissues that do not produce significant amounts of ethylene, and ACO activity is constitutively present in most vegetative tissues. Therefore, the accelerated ethylene biosynthesis that occurs after stimulation is thought to be associated with an increase in the activity of ACS, which is caused by post-transcriptional regulation or the activation of $A C S$ and $A C O$ gene expression [28, 29, 34, 37]. In order to determine whether there is a correlation between AtMEK5-induced ethylene production and the transcription of $A C S$ and $A C O$, their transcript levels were monitored by Q-PCR. We probed for the eight genes that encode activated ACS protein in Arabidopsis [37-40]. However, the transcript levels of ACS2, ACS4, ACS7, ACS9 and $A C S 11$ could not be detected in leaves from $A t M E K 5^{D D}$, AtMEK $5^{K R}$, AtMEK $5^{\mathrm{WT}}$ and Vector transgenic plants after DEX treatment. These results are in agreement with those reported previously [39]. The transcript levels of $A C S 5$ and ACS 8 cannot be monitored by Q-PCR because of multiple bands of amplification when using RT-PCR. Therefore, we can only report the transcript level for $A C S 6$ from Q-PCR. The transcript level of ACS6 was induced strongly in $A t M E K 5^{D D}$ plants after DEX treatment (Figure 2). The transcript level of ACS6 following DEX treatment began to increase after $8 \mathrm{~h}$ and reached its peak after $20 \mathrm{~h}$. The overall increase in transcript level was fifteen-fold. We also monitored the transcript levels of $A C O 1$ and $A C O 2$, which are two functionally characterized genes of the $A C O$ gene family in Arabidopsis [41, 42]. $A C O 1$ was upregulated, while $A C O 2$ was downregulated in AtMEK5 ${ }^{D D}$ plants (Figure 2). The transcript level of $A C O 1$ following DEX treatment began to increase af-
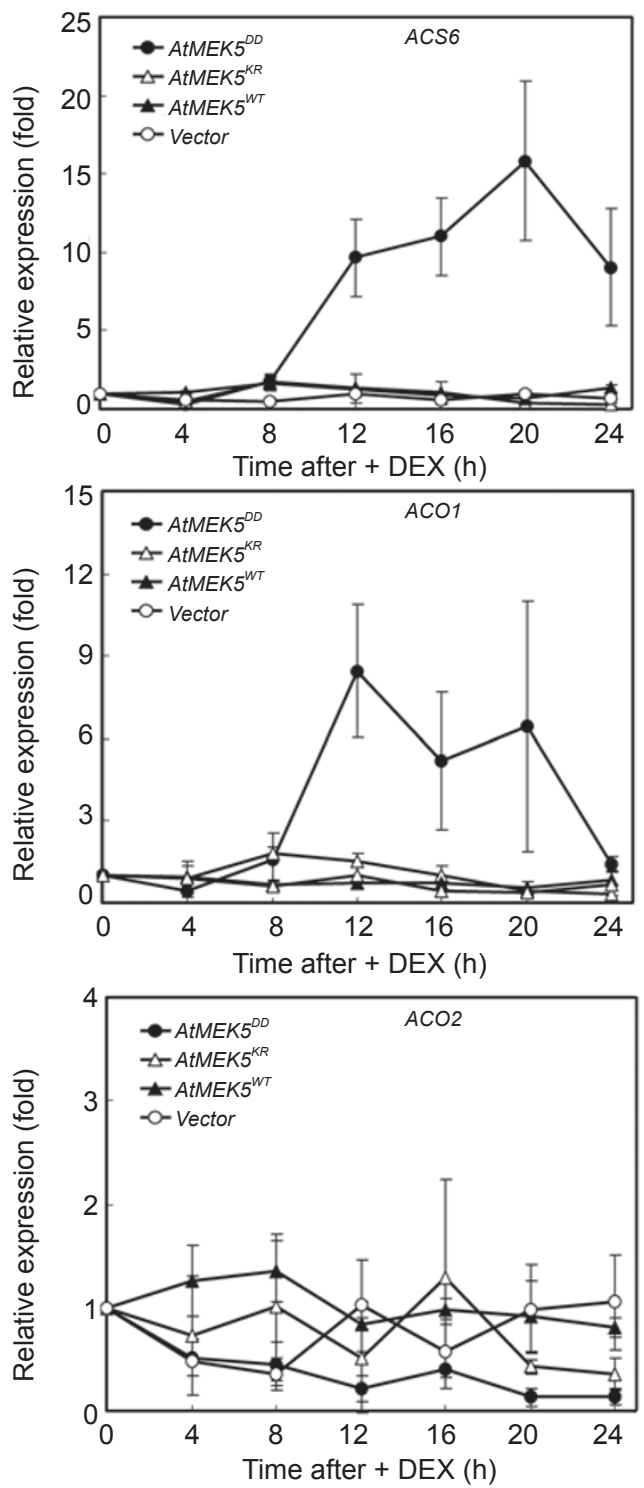

Figure 2 Induction of $A C S$ and $A C O$ gene transcription in At$M E K 5^{D D}, A t M E K 5^{K R}, A t M E K 5^{W T}$ and Vector control transgenic plants after DEX treatment. The samples from transgenic plants were collected at the indicated times and then frozen in liquid nitrogen. RNA extraction and Q-PCR were performed as described in the Materials and Methods section. The results represent the means and standard deviations from triplicate samples. 

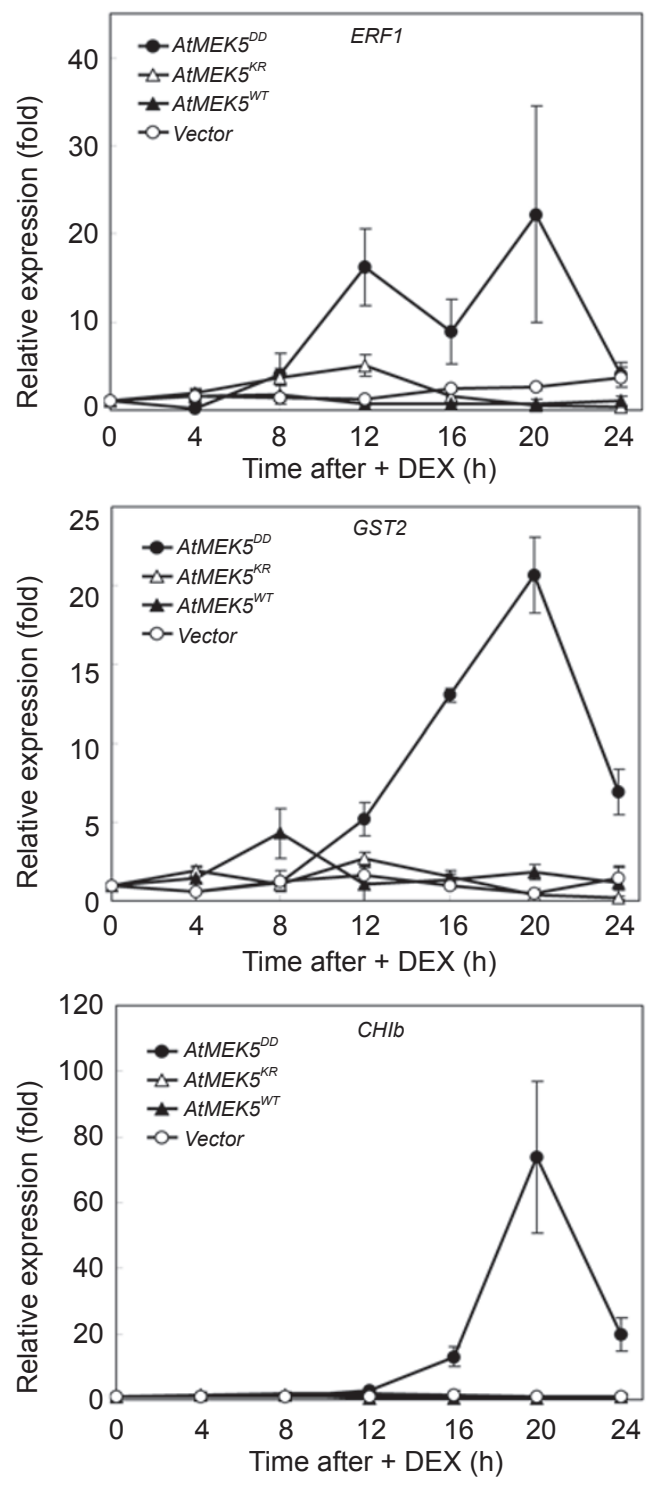

Figure 3 Induction of ethylene response gene transcription in $A t M E K 5^{D D}$, AtMEK $5^{K R}, A t M E K 5^{W T}$ and Vector control transgenic plants after DEX treatment. The samples from transgenic plants were taken at the indicated times and frozen in liquid nitrogen. RNA extraction and Q-PCR were performed as described in the Materials and Methods section. The results represent the means and standard deviations from triplicate samples.

ter $8 \mathrm{~h}$ and increased eight-fold to reach its peak after $12 \mathrm{~h}$. These results suggest that induced transcription of ACS6 and $A C O 1$ may also contribute to the increased ethylene production that is caused by the activation of AtMEK5.

To determine the response to elevated ethylene production that is induced by AtMEK5, we assessed the expression of ERF1, GST2 and CHIb, which have been reported to be downstream responsive genes of the eth- ylene pathway [43, 44]. The transcript levels of the three genes were induced markedly by DEX treatment in $A t$ $M E K 5^{D D}$ plants (Figure 3). The transcript levels of the three genes peaked at $20 \mathrm{~h}$ after DEX treatment. These data indicate that the ethylene production that is induced by the activation of AtMEK5 is sufficient to induce further downstream responses to ethylene.

Inhibition of ethylene biosynthesis and perception effectively delays the cell death that is induced by the activation of AtMEK5

To examine whether an increase of ethylene production has a role in subsequent cell death, cell death and ethylene production were measured in the presence of DEX, inhibitors of ethylene biosynthesis and an ethylene perception antagonist. Ethylene production was reduced considerably in AtMEK $5^{D D}$ transgenic plants treated with DEX after the addition of aminoethoxyvinylglycine (AVG), an inhibitor of ACSs, and $\mathrm{CoCl}_{2}$, an inhibitor of ACOs (Figure 4C). The level of ethylene production in $A t M E K 5^{D D}$ transgenic plants treated with DEX and silver thiosulfate (STS), which is an ethylene perception antagonist, was similar to the level in plants treated with DEX only (Figure $4 \mathrm{C}$ ). In the presence of $\mathrm{AVG}, \mathrm{CoCl}_{2}$ and STS, the extent of cell death was reduced efficiently at $36 \mathrm{~h}$ and $48 \mathrm{~h}$, while the whole leaf was dead at 72 $\mathrm{h}$ after DEX treatment. Cell death did not occur after treatment with $\mathrm{AVG}, \mathrm{CoCl}_{2}$ and STS in the absence of DEX (Figure 4A). As shown in Figure 4B, the extent of electrolyte leakage from leaves of $A t M E K 5^{D D}$ transgenic plants treated with inhibitors plus DEX was much lower than in $A t M E K 5^{D D}$ transgenic plants treated with DEX only. This result also demonstrated that the extent of cell death was reduced by inhibitors of ethylene biosynthesis and perception. The inhibitors did not affect either the expression of AtMEK $5^{\text {DD }}$, as determined by immunoblot analysis with an anti-Flag antibody (Figure 4D, right), or the activity of the downstream MAPKs (AtMAPK3 and AtMAPK6), as measured using an in-gel kinase assay (Figure 4D, left). These results suggest that activation of ACS and ACO activity is required for AtMEK5-induced ethylene production. In addition, ethylene production and perception may be required for AtMEK5-induced cell death.

Ethylene insensitivity delays the cell death that is induced by the activation of AtMEK5

To demonstrate that ethylene perception and signaling are required for cell death, we introduced AtMEK $5^{D D}$ into the ethylene-insensitive mutants etr $1-1$ and ein 2-1. The successful crosses were verified using the triple response (Figure 5A), hygromycin resistance and western 

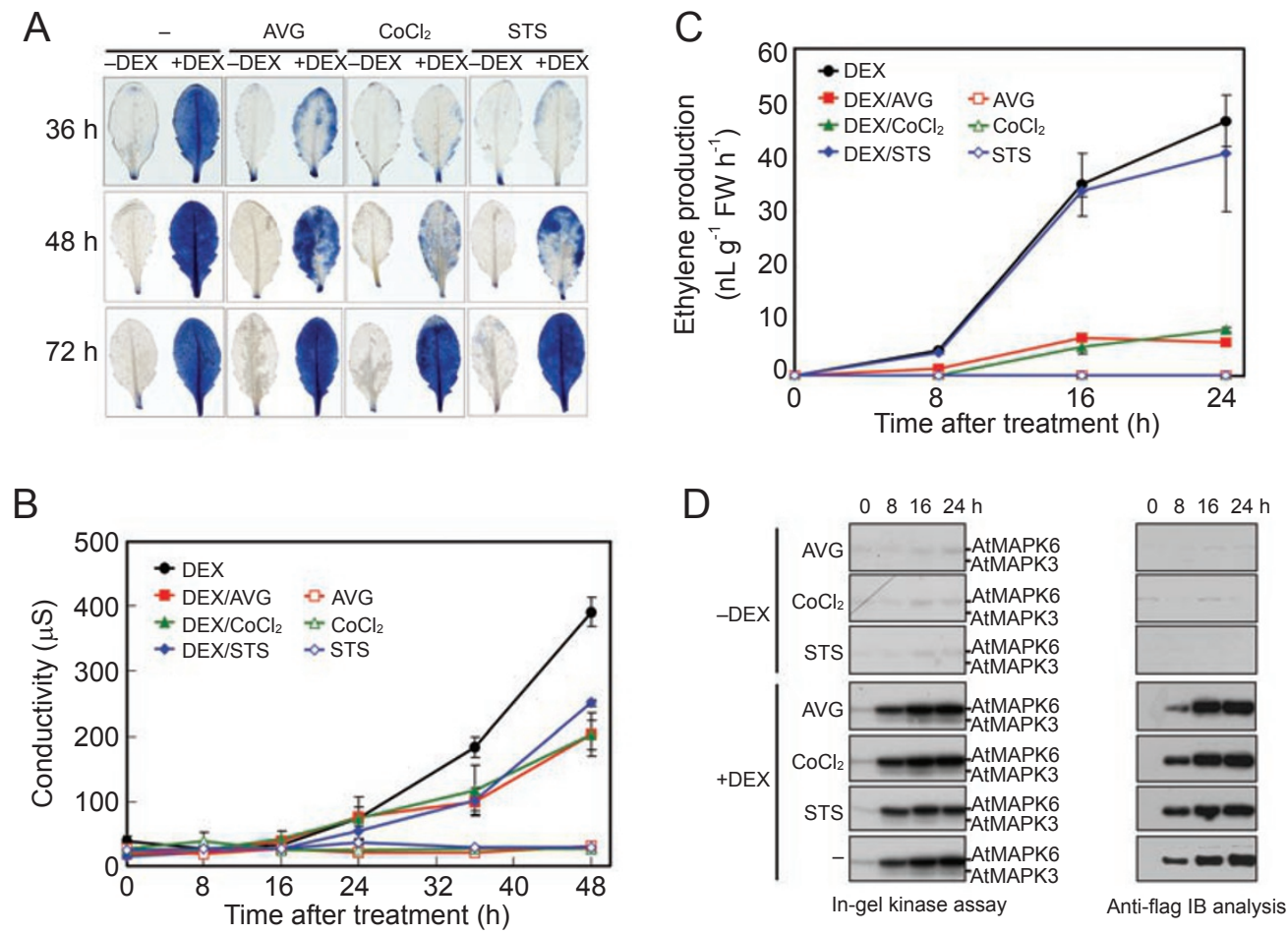

Figure 4 Inhibition of ethylene biosynthesis and perception delayed the onset of AtMEK5-induced cell death. (A) Cell death induced by AtMEK5 ${ }^{\mathrm{DD}}$ expression was delayed by inhibitors of ethylene biosynthesis and perception. Leaves from AtMEK5 $5^{D D}$ transgenic plants were pretreated with $2 \mu \mathrm{M}$ AVG, $100 \mu \mathrm{M} \mathrm{CoCl}$ and $10 \mu \mathrm{M} \mathrm{STS}$ as described in the Materials and Methods section. Cell death was monitored by staining the leaves with Evans blue at 36, 48 and $72 \mathrm{~h}$ after DEX (as +DEX) or $0.05 \%$ ethanol (as -DEX) treatments. (B) Electrolyte leakage is associated with cell death in AtMEK $5^{D D}$ transgenic plants. The results present the means and standard deviations from triplicate samples. (C) Ethylene production induced by AtMEK5 ${ }^{\mathrm{DD}}$ expression was inhibited significantly by the ethylene biosynthesis inhibitors AVG and $\mathrm{CoCl}_{2}$, but not by the ethylene perception inhibitor STS. The results represent the means and standard deviations from triplicate samples. (D) A time course analysis of AtMEK5 ${ }^{\mathrm{DD}}$ induction and endogenous AtMAPK6 and AtMAPK3 activation in leaves from AtMEK5 ${ }^{D D}$ transgenic Arabidopsis plants in the presence of AVG, CoCl2 and STS after DEX (as +DEX) or $0.05 \%$ ethanol (as -DEX) treatments. The expression of AtMEK5 ${ }^{\mathrm{DD}}$ was monitored by immunoblot analysis using anti-Flag M2 antibody (right). The kinase activity of endogenous AtMAPK3 and AtMAPK6 was determined by an in-gel kinase assay (left).

blot methods (data not shown). Cell death in the leaves of AtMEK5 $5^{D D} /$ etr1-1 and AtMEK5 $5^{D D} / e i n 2-1$ plants was reduced markedly in comparison to the leaves of AtME$K 5^{D D}$ plants at $36 \mathrm{~h}$ and $48 \mathrm{~h}$, while the whole leaf was dead at $72 \mathrm{~h}$ after DEX treatment (Figure 5B). As shown in Figure 5C, the extent of electrolyte leakage from the leaves of $A t M E K 5^{D D} /$ etr $1-1$ and $A t M E K 5^{D D} /$ ein2-1 plants was much lower than from those of AtMEK $5^{D D}$ plants after DEX treatment. This result also demonstrates that the extent of cell death was reduced in ethylene insensitive mutants. Ethylene production was reduced slightly in $A t M E K 5^{D D} /$ etr 1-1 and AtMEK5 $5^{D D} /$ ein2-1 plants (Figure 5D), which may be due to feedback regulation of ethylene biosynthesis by the ethylene response. The comparable AtMEK $5^{\text {DD }}$ protein and activities of downstream MAPKs were shown in AtMEK5 $5^{D D} /$ etr 1-1, AtMEK $5^{D D} /$ ein2-1 and $A t M E K 5^{D D}$ plants (Figure 5E). These data confirmed that ethylene signaling perception is required for the regulation of AtMEK5-induced cell death.

\section{Discussion}

A diverse array of stresses, which include pathogen infection, wounding, UV irradiation, drought, high osmolarity, ozone and oxidative stress, have been shown to activate AtMAPK3 or AtMAPK6, or both, in Arabidopsis and their orthologs in other plant species [12, 26, $45,46]$. These stresses have also been reported to induce ethylene production [18, 28, 34, 47-50]. The long-lasting activation of AtMAPK6 alone or both AtMAPK3 and AtMAPK6 by their upstream MAPKKs (namely AtMEK4 and AtMEK5 in Arabidopsis, and their ortholog NtMEK2 in tobacco) induces HR-like cell death [20,24]. Expression of the NtMEK2 active mutant also induces an 
A

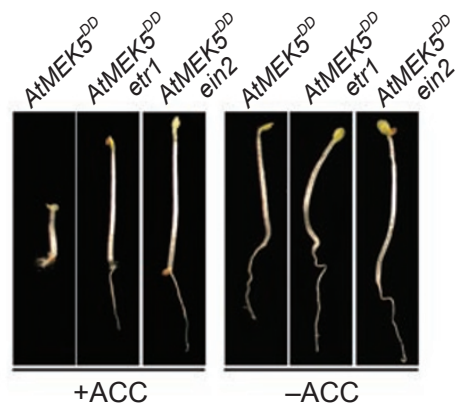

B

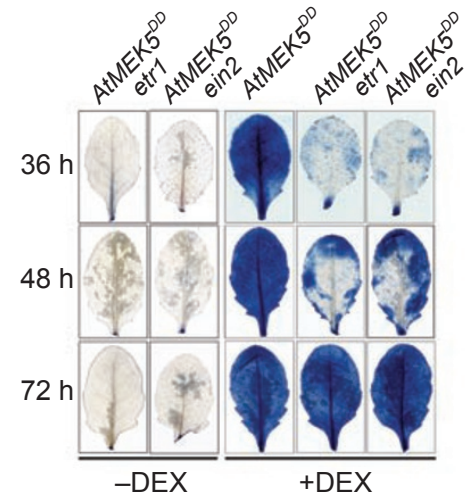

C

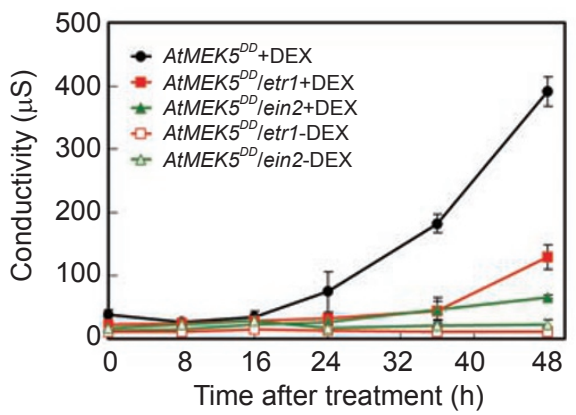

D

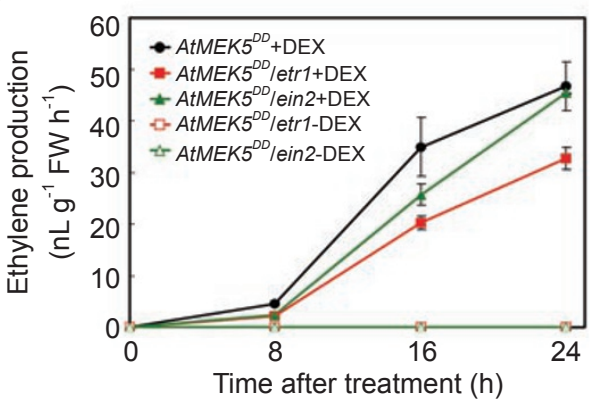

$E$

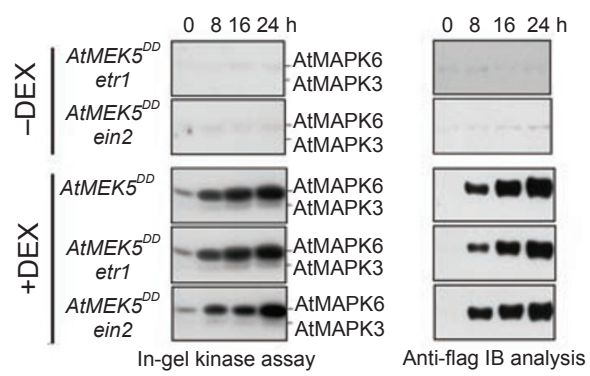

Figure 5 Ethylene insensitivity delayed the onset of AtMEK5-induced cell death. (A) A triple response of AtMEK5 ${ }^{D D}$, AtME$K 5^{D D} /$ etr1 and $A t M E K 5^{D D} / e i n 2$ plants in the presence or absence of $1 \mathrm{mM} \mathrm{ACC}$. (B) Cell death induced by the activation of AtMEK5 was delayed in AtMEK $5^{D D} /$ etr1 and AtMEK5 $5^{D D} / e i n 2$ plants. Cell death was monitored by staining the leaves from AtME$K 5^{D D}, A t M E K 5^{D D} /$ etr 1 and $A t M E K 5^{D D} / e i n 2$ plants with Evans blue at 36,48 and $72 \mathrm{~h}$ after DEX (as +DEX) or $0.05 \%$ ethanol (as -DEX) treatments. (C) Electrolyte leakage is associated with cell death in $A t M E K 5^{D D} /$ etr1 and AtMEK5 $5^{D D} /$ in 2 transgenic plants. The results present the means and standard deviations from triplicate samples. (D) Ethylene production in AtME$K 5^{D D} /$ etr 1 and $A t M E K 5^{D D} / e i n 2$ after DEX (as +DEX) or $0.05 \%$ ethanol (as -DEX) treatments. The rates of ethylene production were measured at the times indicated. Results represent the means and standard deviations of triplicate samples. (E) A time course analysis of AtMEK5 $5^{\text {DD }}$ induction and endogenous AtMAPK6 and AtMAPK3 activation in leaves from AtMEK5 ${ }^{D D}$, AtME$K 5^{D D}$ etr1 and AtMEK $5^{D D} / e i n 2$ plants. The expression of AtMEK5 ${ }^{\mathrm{DD}}$ was monitored by immunoblot analysis using anti-Flag M2 antibody (right). The kinase activity of endogenous AtMAPK3 and AtMAPK6 was determined by an in-gel kinase assay (left).

impressive increase in ethylene production in transgenic tobacco and Arabidopsis [18, 20, 24, 34]. This ethylene production is due to the increased activity of ACS. The increased activity of ACS is caused by the accumulation of phosphorylated ACS2/ACS6 [34] and newly translated ACS2/ACS6 [18]. However, the role of ethylene in cell death has not yet been elucidated. The results of this investigation have established that the expression of AtMEK $5^{\mathrm{DD}}$, which is an active mutant of AtMEK5, induces a striking increase in ethylene production (Figure 1C). We have also explored the role of ethylene in the HRlike cell death that is caused by AtMEK5. 
Various lines of evidence show that ethylene biosynthesis and/or ethylene signaling are involved in the regulation of cell death. Studies involving the use of inhibitors of ethylene biosynthesis [51-53], ethylene perception antagonists $[47,53,54]$ and ethylene-insensitive mutants with deficiencies in ethylene signaling [54] have revealed significantly reduced lesion formation and expansion in leaves that are exposed to ozone. The role of ethylene in the pathogenesis of disease and defense responses in infected plants has been studied extensively [28, 55]. For example, the onset of HR-like cell death in tobacco infected with TMV $[18,56]$, tomato infected with Cladosporium fulvum [57] and rice infected with Magnaporthe grisea [58] was accompanied by a large burst of ethylene production [59]. Significant suppressed TMV-induced HR-like cell death and expansion was observed in tobacco treated with inhibitors of ethylene biosynthesis or ethylene perception antagonists $[56,60]$. Knoester and colleagues reported that ethylene-insensitive tobacco (Tetr) plants, transformed with a mutant etrl-1 gene from Arabidopsis, had reduced virus-induced lesion expansion [56]. We observed that HR-like cell death began at the leaf edges of $A t M E K 5^{D D}$ plants at $24 \mathrm{~h}$, and that the whole leaf was dead at $36 \mathrm{~h}$ after DEX treatment (Figure 1A). This start time of cell death is the same as has been reported previously [24]. However, the time at which an increase in ethylene could be detected was well before the start of cell death (Figure 1). Kim et al. reported that the expression of NtMEK $2^{\mathrm{DD}}$, which is an active mutant of NtMEK2, induced the ethylene biosynthesis before the appearance of HR-like cell death in tobacco [18]. These results suggest that AtMEK5- and NtMEK2-induced ethylene production is not a consequence of cell death.

To appreciate the role of ethylene in AtMEK5-induced cell death, we performed two sets of experiments. First, we monitored the onset of cell death using $\mathrm{CoCl}_{2}$ and AVG, two widely used inhibitors of ethylene biosynthesis. If the cell death was ethylene-independent, we would expect that the time of whole-leaf death would not be affected after inhibiting ethylene biosynthesis. However, we observed that cell death was delayed considerably when ethylene biosynthesis was blocked by two inhibitors (Figure 4A). Second, we blocked ethylene signaling by using the ethylene receptor antagonist STS and the ethylene insensitive mutants etrl and ein2. The time of whole-leaf death was delayed in the presence of STS and when $A t M E K 5^{D D}$ was introduced into ethylene insensitive mutants etrl and ein 2 (Figure 4A and Figure 5B ). On the basis of our results, we concluded that ethylene signaling is required for the acceleration of AtMEK5induced cell death.

Inhibiting ethylene biosynthesis or blocking ethylene signaling significantly delayed, but did not completely abolish cell death, which suggests that other signaling pathway(s) might also be involved in the regulation of AtMEK5-induced cell death. $\mathrm{H}_{2} \mathrm{O}_{2}$ has been established as an important trigger for HR-like cell death in plants that are challenged with pathogen [61]. The accumulation of $\mathrm{H}_{2} \mathrm{O}_{2}$ has been shown to be required for the cell death that is caused by other stresses [53]. Since large amounts of $\mathrm{H}_{2} \mathrm{O}_{2}$ are generated in AtMEK5-induced cell death [24], $\mathrm{H}_{2} \mathrm{O}_{2}$ may be an important component in causing cell death. Therefore, we tried to explore the role of $\mathrm{H}_{2} \mathrm{O}_{2}$ in cell death by using inhibitors, such as diphenyleneiodonium, $\mathrm{KCN}$ and $\mathrm{NaN}_{3}$, to block the production of $\mathrm{H}_{2} \mathrm{O}_{2}$. Unfortunately, we were unable to reach any conclusions from these experiments (data not shown) because the inhibitors themselves also caused cell death in controls. To further elucidate the role of $\mathrm{H}_{2} \mathrm{O}_{2}$ in cell death, AtME$K 5^{D D}$ needed to be transformed and expressed in mutants that are impaired in $\mathrm{H}_{2} \mathrm{O}_{2}$ generation or defective in $\mathrm{H}_{2} \mathrm{O}_{2}$ signaling.

\section{Materials and Methods}

\section{Plant growth conditions and treatments}

Wild-type and transgenic Arabidopsis thaliana (Columbia ecotype) plants were grown in a growth chamber at $22{ }^{\circ} \mathrm{C}$ with a $12 \mathrm{~h}$ light : $12 \mathrm{~h}$ dark photoperiod. Fully expanded leaves of 4-week-old plants were used for the experiments.

Transgene expression was induced by incubating the leaves in $15 \mu \mathrm{M}$ of DEX (Sigma) solution. For treatment with inhibitors of ethylene biosynthesis or receptors, the leaves were incubated for $2 \mathrm{~h}$ in $100 \mu \mathrm{M}$ of $\mathrm{CoCl}_{2}$, or $2 \mu \mathrm{M}$ of AVG (Sigma), or $10 \mu \mathrm{M}$ of STS (freshly prepared before use from stock solutions of STS and silver nitrate in a 4:1 molar ratio) before DEX was added. Samples were harvested at the indicated time. The samples were frozen in liquid nitrogen and stored at $-80^{\circ} \mathrm{C}$ until use.

\section{Measurement of ethylene content in leaves}

Detached leaves $(\sim 0.3 \mathrm{~g})$ were treated with DEX in a $10 \mathrm{ml}$ vial sealed with a rubber plug. $1 \mathrm{ml}$ of the gas was removed from the vial and introduced to a gas chromatograph equipped with a flame ionization detector (GC-7AG, Shimadzu, Tokyo, Japan). The amount of ethylene was estimated by comparing it with an ethylene standard. The data are displayed as the mean \pm the standard deviation from triplicate samples. All the experiments were repeated for three times.

\section{Generation of crosses}

Arabidopsis mutants of etr1-1 (CS237, on a Col-0 background) and ein2-1 (CS3071, on a Col-0 background) were obtained from ABRC. The etr1-1 and ein2-1 mutants were crossed into an $A t M E K 5^{D D}$ transgenic background. AtMEK5 $5^{D D}$ was identified using hygromysin resistance and transgene expression. The etr1-1 and ein2-1 mutants were identified on the basis of the ethyleneinsensitive phenotype. Homozygous F3 plants were used for the experiments. 
Detection of cell death in leaves using Evans blue staining

Cell death was measured in the leaves by staining with Evans blue according to the method described by Baker and Norton [62], but with some modifications. Leaves were taken at the indicated times and soaked in $10 \mathrm{ml}$ of $0.25 \%$ Evans blue. They were then washed briefly in $10 \mathrm{ml}$ water. Leaves were de-stained in boiling $96 \%$ ethanol for $10 \mathrm{~min}$. Then the leaves were transferred to a $60 \%$ glycerol solution.

\section{Measurement of electrolyte leakage from leaves}

At various times after treatment about $0.1 \mathrm{~g}$ of leaves was sampled from the plants. After brief rising, the leaves were shaken in 3 $\mathrm{ml}$ of distilled water on a rotary shaker at $100 \mathrm{rpm}$ for $1 \mathrm{~h}$ at room temperature. The conductivity of the solution was measured with a conductivity meter (model 3173R, JENCO, China).

\section{Quantitative RT-PCR analysis}

Total RNA was extracted from samples using Trizol (Invitrogen) according to the manufacturer's instructions. Reverse transcription (RT) was performed using $2.4 \mu \mathrm{g}$ of total RNA and $0.6 \mu \mathrm{g}$ of oligo (dT)16 primer with M-MLV reverse transcriptase (Promega). Aliquots of the products of RT were used as a template for quantitative PCR (Q-PCR). Q-PCR was run with SYBR green fluorophore (Molecular Probes), $100 \mathrm{nM}$ primer and a $1 \mu \mathrm{l}$ aliquot of RT product in a $20 \mu \mathrm{l}$ final volume per reaction. PCR analysis was performed using a DNA Engine Opticon II system (MJ Research) according to the manufacturer's instructions. Agarose gel electrophoresis and thermal denaturation (melt curve analysis) were used to confirm specific replicon formations. For each reaction, the threshold cycle value (CT) was determined by setting the threshold within the logarithmic amplification phase. The CT values were converted to relative gene expression levels using the $2-\Delta \mathrm{CT}$ method. After normalization to an Actin 8 control, the relative levels of gene expression were calculated. Q-PCR reactions were done in triplicate and averaged for each time point. Primer pairs used for Q-PCR were:

ACS6 (At4g11280) forward: 5'-CCG GGA ATG TTT GAA GTC TCT TG-3'; ACS6 reverse: 5'-CGG TCT TAA GTC TGT GCA CGG-3'; ACO1 (At1g05010) forward: 5'-TCC CGA TCA TCA ATC TCG AG-3';

ACO1 reverse: 5'-CAG TGG CCA ATG GTC CAA C-3'; ACO2 (Atlg62380) forward: 5'-CAG TGG CCA ATG GTC CAA C-3' ACO2 reverse: 5'-CTA ACC TAT ACG ACA TCC CTG-3' ERF1 (At3g23240) forward: 5'-CGG CGG AGA GAG TTC AAG AGT C-3'; ERF1 reverse: 5'-TCC CAC TAT TTT CAG AAG ACC CC-3'; GST2 (At4g02520) forward: 5'-ATG GCA GGT ATC AAA GTT TTC GG-3'; GST2 reverse: 5'-ATT TCT CAC TGA ACC TTC TCG-3'; $C H I-b$ (At3g12500) forward: 5'-ATC ACC GCT GCA AAG TCC TTC-3'; $C H I-b$ reverse: $5^{\prime}$-TGC TGT AGC CCA TCC ACC TG-3'; Actin 8 (At1g49240) forward: 5'-GGT GAT GGT GTG TCT-3'; Actin 8 reverse: 5'-ACT GAG CAC AAT GTT AC-3'.

\section{Protein extraction and immunoblot analysis}

Total protein was extracted from leaf tissues by grinding with plastic pestles in extraction buffer (100 mM HEPES, $\mathrm{pH} 7.5,5$ mM EDTA, 5 mM EGTA, $10 \mathrm{mM} \mathrm{Na} V_{2}, 10 \mathrm{mM} \mathrm{NaF}, 50 \mathrm{mM}$ $\beta$-glycerophosphate, $10 \mathrm{mM}$ dithiothreitol, $1 \mathrm{mM}$ phenylmethylsulfonyl fluoride, $5 \mu \mathrm{g} / \mathrm{ml}$ leupeptin, $5 \mu \mathrm{g} / \mathrm{ml}$ aprotinin and $5 \%$ glycerol). After centrifugation at $10000 \mathrm{~g}$ for $20 \mathrm{~min}$, supernatants were transferred into clean tubes. The protein concentration was determined using the Bio-Rad protein assay kit (Bio-Rad), using bovine serum albumin as the standard. For western blot analysis, $7.5 \mu \mathrm{g}$ of total protein per lane was separated on a $10 \%$ SDS polyacrylamide gel (SDS-PAGE). After electrophoresis, the proteins were electro-transferred onto nitrocellulose membranes. After blocking for $1 \mathrm{~h}$ in TBST buffer $(50 \mathrm{mM}$ Tris-HCl, $\mathrm{pH} 7.5$, $150 \mathrm{mM} \mathrm{NaCl}, 0.05 \%$ Tween 20 ) with $5 \%$ fat-free dried milk at room temperature, the membranes were incubated with anti-Flag antibody M2 (Sigma, 1:10 000 dilution) for $2 \mathrm{~h}$. Following three washes with TBST buffer, the membranes were incubated with horseradish peroxidase-conjugated goat anti-mouse IgG as secondary antibody (Sigma, 1:10 000 dilution). After three washes with TBST buffer, the membranes were then visualized using an enhanced Lumi-Light Western Blotting Substrate kit (Roche), following the manufacturer's instructions.

\section{In-gel kinase activity assay}

The in-gel kinase activity assay was performed using a previously described method [24]. In brief, an aliquot containing 7.5 $\mu \mathrm{g}$ of protein extract was electrophoresed on $10 \%$ SDS-polyacrylamide gels embedded with $0.1 \mathrm{mg} / \mathrm{ml}$ myelin basic protein in separating gel as a substrate for kinase. After electrophoresis, the SDS was removed from the gel by washing with washing buffer (25 mM Tris- $\mathrm{HCl}, \mathrm{pH} 7.5,0.5 \mathrm{mM}$ dithiothreitol, $0.1 \mathrm{mM} \mathrm{Na}_{3} \mathrm{VO}_{4}$, $5 \mathrm{mM} \mathrm{NaF}, 0.5 \mathrm{mg} / \mathrm{ml}$ bovine serum albumin, and $0.1 \%$ Triton $\mathrm{X}-100)$ three times for $30 \mathrm{~min}$ each at room temperature. The proteins were then renatured in $25 \mathrm{mM}$ Tris- $\mathrm{HCl}, \mathrm{pH} 7.5,1 \mathrm{mM}$ dithiothreitol, $0.1 \mathrm{mM} \mathrm{Na}_{3} \mathrm{VO}_{4}, 5 \mathrm{mM} \mathrm{NaF}$ at $4{ }^{\circ} \mathrm{C}$ overnight with three changes of the buffer. The gel was incubated at room temperature in $100 \mathrm{ml}$ of reaction buffer $(25 \mathrm{mM}$ Tris- $\mathrm{HCl}, \mathrm{pH} 7.5,2$ mM EGTA, $12 \mathrm{mM} \mathrm{MgCl} 2,1 \mathrm{mM}$ dithiothreitol, $0.1 \mathrm{mM} \mathrm{Na}_{3} \mathrm{VO}_{4}$ ) for $30 \mathrm{~min}$. Phosphorylation was performed for $1.5 \mathrm{~h}$ at room temperature in $30 \mathrm{ml}$ reaction buffer that contained $200 \mathrm{nM}$ ATP and $50 \mu \mathrm{Ci}$ of $\gamma^{3}{ }^{32} \mathrm{P}$-ATP $(3000 \mu \mathrm{Ci} / \mathrm{mmol})$. The reaction was stopped by transferring the gel into a solution of $5 \%$ trichloroacetic acid $(\mathrm{w} / \mathrm{v})$ and $1 \%$ sodium pyrophosphate $(\mathrm{w} / \mathrm{v})$. The unincorporated radioactivity was subsequently removed by washing the gel for $5 \mathrm{~h}$ at room temperature with five changes. The gel was dried on Whatman 3MM paper and subjected to autoradiography. Prestained size markers (NEB) were used to calculate the sizes of the kinases.

\section{Acknowledgments}

This work was supported by National Basic Research Program of China (Grant No. 2003CB114304), the National Natural Science Foundation of China (Grant Nos. 30421002, 30770203, and 30370140), NCET 04-0131 and the Fok Ying Tung Education Foundation (Grant No. 91022) to D Ren, and the National Natural Science Foundation of China (Grant No. 30770128) to G Liu. 


\section{References}

1 Pennell RI, Lamb C. Programmed cell death in plants. Plant Cell 1997; 9:1157-1168.

2 Overmyer K, Brosche M, Kangasjarvi J. Reactive oxygen species and hormonal control of cell death. Trends Plant Sci 2003; 8:335-342.

3 Dangl JL, Jones JDG. Plant pathogens and integrated defence responses to infection. Nature 2001; 411:826-833.

4 Dixon RA. Natural products and plant disease resistance. $\mathrm{Na}$ ture 2001; 411:843-847.

5 Glazebrook J. Contrasting mechanisms of defense against biotrophic and necrotrophic pathogens. Annu Rev Phytopathol 2005; 43:205-227.

6 Greenberg JT, Yao N. Microreview The role and regulation of programmed cell death in plant-pathogen interactions. Cell Microbiol 2004; 6:201-211.

7 Martin GB, Bogdanove AI, Sessa G. Understanding the functions of plant disease resistance proteins. Annu Rev Plant Biol 2003; 54:23-61.

8 Torres MAD, Jeffery L. Functions of the respiratory burst oxidase in biotic interactions, abiotic stress and development. Curr Opin Plant Biol 2005; 8:397-403.

9 Zhang S, Klessig DF. Pathogen-induced MAP kinase in tobacco. Res Prob Cell Differ 2000; 27:65-84.

10 Somssich IE, Hahlbrock K. Pathogen defence in plants - a paradigm of biological complexity. Trends Plant Sci 1998; 3:86-90.

11 Scheel D. Resistance response physiology and signal transduction. Curr Opin Plant Biol 1998; 1:305-310.

12 Jonak C, Okresz L, Bogre L, Hirt H. Complexity, Cross talk and integration of plant MAP Kinase signalling. Curr Opin Plant Biol 2002; 5:415-424.

13 Chang L, Karin M. Mammalian MAP kinase signalling cascades. Nature 2001; 410:37-40.

14 Widmann C, Gibson S, Jarpe MB, Johnson GL. Mitogen-activated protein kinase: conservation of a three-kinase module from yeast to human. Physiol Rev 1999; 79:143-180.

15 Nakagami H, Pitzschke A, Hirt H. Emerging MAP kinase pathways in plant stress signalling. Trends Plant Sci 2005; 10:339-346.

16 Pedley KF, Martin GB. Role of mitogen-activated protein kinases in plant immunity. Cur Opin Plant Biol 2005; 8:541-547.

17 Liu Y, Jin H, Yang KY, et al. Interaction between two mitogenactivated protein kinases during tobacco defense signaling. Plant J 2003; 34:149-160.

18 Kim CY, Liu Y, Thorne ET, et al. Activation of a stress-responsive mitogen-activated protein kinase cascade induces the biosynthesis of ethylene in plants. Plant Cell 2003; 15:2707-2718.

19 Hirt H. MAP kinase in plant signal transduction. Res Prob Cell Differ 2000; 27:1-9.

20 Yang KY, Liu Y, Zhang S. Activation of a mitogen-activated protein kinase pathway is involved in disease resistance in tobacco. Proc Natl Acad Sci USA 2001; 98:741-746.

21 Ren D, Yang KY, Li GJ, Liu Y, Zhang S. Activation of Ntf4, a tobacco mitogen-activated protein kinase, during plant defense response and its involvement in hypersensitive response-like cell death. Plant Physiol 2006; 141:1482-1493.

22 Zhang S, Liu Y. Activation of salicylic acid-induced protein kinase, a mitogen-activated protein kinase, induces multiple defense responses in tobacco. Plant Cell 2001; 13:1877-1889.

23 Jin H, Liu Y, Yang KY, et al. Function of a mitogen-activated protein kinase pathway in $\mathrm{N}$ gene-mediated resistance in tobacco. Plant J 2003; 33:719-731.

24 Ren D, Yang H, Zhang S. Cell death mediated by MAPK is associated with hydrogen peroxide production in Arabidopsis. $J$ Biol Chem 2002; 277:559-565.

25 Pedley KF, Martin GB. Identification of MAPKs and their possible MAPK kinase activators involved in the Ptomediated defense response of tomato. J Biol Chem 2004; 279:49229-49235.

26 MAPK group. Mitogen-activated protein kinase cascades in plants: a new nomenclature. Trends Plant Sci 2002; 7:301-308.

27 Arshad M, Frakenberger WT. Ethylene. Dordrecht, NL: Kluwer Academic Press 2002:11-50.

28 Wang KLC, Li H, Ecker JR. Ethylene biosynthesis and signaling networks. Plant Cell 2002; 14:S131-S151.

29 Kende H. Ethylene biosynthesis. Annu Rev Plant Physiol Plant Mol Biol 1993; 44:283-307.

30 Adams DO, Yang SF. Ethylene biosynthesis: identification of 1-aminocyclopropane-1-carboxylic acid as an intermediate in the conversion of methionine to ethylene. Proc Natl Acad Sci USA 1979; 76:170-174.

31 Spanu P, Grosskopf DG, Felix G, Boller T. The apparent turnover of 1-aminocyclopropane-1-carboxylate synthase in tomato cells is regulated by protein phosphorylation and dephosphorylation. Plant Physiol 1994; 106:529-535.

32 De Laat AMM, Van Loon LC. The relationship between simulated ethylen production and symptom expression in virus-infected tobacco leaves. Physiol Plant Pathol 1983; 22:261-273.

33 Zhang S, Klessig DF. Resistance gene N-mediated de novo synthesis and activation of a tobacco mitogen-activated protein kinase by tobacco mosaic virus infection. Proc Natl Acad Sci USA 1998; 95:7433-7438.

34 Liu Y, Zhang S. Phosphorylation of 1-aminocyclopropane1-carboxylic acid synthase by MPK6, a stress-responsive mitogen-activated protein kinase, induces ethylene biosynthesis in Arabidopsis. Plant Cell 2004; 16:3386-3399.

35 Penninckx IAMA, Thomma BPHJ, Buchala A, Metraux JP, Broekaert WF. Concomitant activation of jasmonate and ethylene response pathways is required for induction of a plant defensin gene in Arabidopsis. Plant Cell 1998; 10:2103-2114.

36 Cohn JR, Martin GB. Pseudomonas syringae pv. tomato type III effectors AvrPto and AvrPtoB promote ethylene-dependent cell death in tomato. Plant J 2005; 44:139-154.

37 Chae HS, Kieber JJ. Eto Brute? Role of ACS turnover in regulating ethylene biosynthesis. Trends Plant Sci 2005; 10:291-296.

38 Liang X, Abel S, Keller JA, Shen NF, Theologis A. The 1-aminocyclopropane-1-carboxylate synthase gene family of Arabidopsis thaliana. Proc Natl Acad Sci USA 1992; 89:11046-11050.

39 Yamagami T, Tsuchisaka A, Yamada K, et al. Biochemical diversity among the 1-amino-cyclopropane-1-carboxylate synthase isozymes encoded by the Arabidopsis gene family. J Biol Chem 2003; 278:49102-49112.

40 Tsuchisaka A, Theologis A. Heterodimeric interactions among the 1-amino-cyclopropane-1-carboxylate synthase polypep- 
tides encoded by the Arabidopsis gene family. Proc Natl Acad Sci USA 2004; 101:2275-2280.

41 Raz V, Ecker JR. Regulation of differential growth in the apical hook of Arabidopsis. Development 1999; 126:3661-3668.

42 Gomez-Lim MA, Valdes-Lopez V, Cruz-Hernandez A, Saucedo-Arias LJ. Isolation and characterization of a gene involved in ethylene biosynthesis from Arabidopsis thaliana. Gene 1993; 134:217-221.

43 Ouaked F, Rozhon W, Lecourieux D, Hirt H. A MAPK pathway mediates ethylene signaling in plants. EMBO J 2003; 22:1282-1288.

44 Alonso JM, Hirayama T, Roman G, Nourizadeh S, Ecker JR. EIN2, a Bifunctional transducer of ethylene and stress responses in Arabidopsis. Science 1999; 284:2148-2152.

45 Zhang S, Klessig DF. MAPK cascades in plant defense signaling. Trends Plant Sci 2001; 6:520-527.

46 Tena G, Asai T, Chiu WL, Sheen J. Plant mitogen-activated protein kinase signaling cascades. Curr Opin Plant Biol 2001; 4:392-400.

47 Vahala J, Ruonala R, Keinanen M, Tuominen H, Kangasjarvi J. Ethylene insensitivity modulates ozone-induced cell death in birch. Plant Physiol 2003; 132:185-195.

48 Mckeon TA, Fernandez-Maculet LC, Yang SF. Biosynthesis and metabolism of ethylene. In Plant hormones. PJ Davies ed. Dordrecht, NL: Kluwer Academic Press 1995:118-139.

49 Johnson PR, Ecker JR. The ethylene gas signal transduction pathway: A molecular perspective. Annu Rev Genet 1998; 32:227-254.

50 Bleecker AB, Kende H. Ethylene: A gaseous signal molecule in plants. Annu Rev Cell Dev Biol 2000; 16:1-18.

51 Wenzel AA, Schlautmann H, Jones CA, Kuppers K, Mehlhorn H. Aminoethoxyvinylglycine, cobalt and ascorbic acid all reduce ozone toxicity in mung beans by inhibition of ethylene biosynthesis. Physiol Plant 1995; 93:286-290.

52 Tuomainen J, Betz C, Kangasjarvi J, et al. Ozone induction of ethylene emission in tomato plants: regulation by differen- tial accumulation of transcripts for the biosynthetic enzymes. Plant J 1997; 12:1151-1162.

53 Moeder W, Barry CS, Tauriainen AA, et al. Ethylene synthesis regulated by biphasic induction of 1-aminocyclopropane1-carboxylic acid synthase and 1-aminocyclopropane-1-carboxylic acid oxidase genes is required for hydrogen peroxide accumulation and cell death in ozone-exposed tomato. Plant Physiol 2002; 130:1918-1926.

54 Overmyer K, Tuominen H, Kettunen R, et al. Ozone-sensitive Arabidopsis rcd1 mutant reveals opposite roles for ethylene and jasmonate signaling pathways in regulating superoxidedependent cell death. Plant Cell 2000; 12:1849-1862.

55 Dong X. SA, JA, ethylene, and disease resistance in plants. Cur Opin Plant Biol 1998; 1:316-323.

56 Knoester M, Linthorst HJM, Bol JF, Van Loon LC. Involvement of ethylene in lesion development and systemic acquired resistance in tobacco during the hypersensitive reaction to tobacco mosaic virus. Physiol Mol Plant Pathol 2001; 59:45-57.

57 Hammond-Kosack KE, Jones JDG. Resistance gene-dependent plant defense responses. Plant Cell 1996; 8:1773-1791.

58 Iwai T, Miyasaka A, Seo S, Ohashi Y. Contribution of ethylene biosynthesis for resistance to blast fungus infection in young rice plants. Plant Physiol 2006; 142:1202-1215.

59 Van Loon LC, Geraats BPJ, Linthorst HJM. Ethylene as a modulator of disease resistance in plants. Trends Plant Sci 2006; 11:184-191.

60 Ohtsubo N, Mitsuhara I, Koga M, Seo S, Ohashi Y. Ethylene promotes the necrotic lesion formation and basic PR gene expression in TMV-infected tobacco. Plant Cell Physiol 1999; 40:808-817.

61 Levine A, Tenhaken R, Dixon R, Lamb C. $\mathrm{H}_{2} \mathrm{O}_{2}$ from the oxidative burst orchestrates the plant hypersensitive disease resistance response. Cell 1994; 79:583-593.

62 Baker CJ, Norton MM. An improved method for monitoring cell death in cell suspension and leaf disc assays using evans blue. Plant Cell Tiss Org 1994; 39:7-12. 